\title{
Sex Differences in Outcome After Thrombectomy for Acute Ischemic Stroke are Explained by Confounding Factors
}

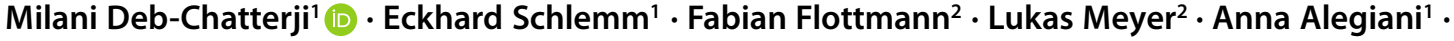 \\ Caspar Brekenfeld ${ }^{2}$. Jens Fiehler ${ }^{2}$. Christian Gerloff' ${ }^{1}$ Götz Thomalla' . GSR-ET Investigators
}

Received: 10 September 2020 / Accepted: 21 November 2020 / Published online: 21 December 2020

(c) The Author(s) 2020

\begin{abstract}
Purpose The aim of this study was to analyze sex differences in outcome after thrombectomy for acute ischemic stroke in clinical practice in a large prospective multicenter registry.

Methods Data of consecutive stroke patients treated with thrombectomy (June 2015-April 2018) derived from an industry-independent registry (German Stroke Registry-Endovascular Treatment) were prospectively analyzed. Multivariable binary logistic regression analyses were applied to determine whether sex is a predictor of functional independence outcome (defined as a modified Rankin scale [mRS] 0-2) 90 days after stroke.

Results In total, 2316 patients were included in the analysis, $1170(50.5 \%)$ were female and $1146(49.5 \%)$ were male. Women were older (median age 78 vs. 72 years; $p<0.001$ ) and more frequently had a prestroke functional impairment defined by $\mathrm{mRS}>1(24.8 \%$ vs. $14.1 \% ; p<0.001)$. In unadjusted analyses, independent outcome at 90 days was less frequent in women $(33.2 \%)$ than men $(40.6 \% ; p<0.001)$. Likewise, mortality was higher in women than in men $(30.7 \%$ vs. $26.4 \%$; $p=0.024)$. In adjusted regression analyses, however, sex was not associated with outcome. Lower age, a lower baseline National Institutes of Health Stroke Scale score, a higher Alberta Stroke Program Early CT score, prestroke functional independence, successful reperfusion, and concomitant intravenous thrombolysis therapy predicted independent outcome. Conclusion Women showed a worse functional outcome after thrombectomy for acute ischemic stroke in clinical practice; however, after adjustment for crucial confounders sex was not a predictor of outcome. The difference in outcome thus appears to result from differences in confounding factors such as age and prestroke functional status.
\end{abstract}

Keywords Ischemia $\cdot$ Gender difference $\cdot$ Outcome predictors $\cdot$ Intervention $\cdot$ Angiography

Availability of Data and Material Data are available upon reasonable request.

Supplementary Information The online version of this article (https://doi.org/10.1007/s00062-020-00983-2) contains supplementary material, which is available to authorized users.

Milani Deb-Chatterji

m.deb-chatterji@uke.de

1 Department of Neurology, University Medical Center

Hamburg-Eppendorf, Hamburg, Germany

2 Department of Interventional Neuroradiology and Diagnostics, University Medical Center Hamburg-Eppendorf, Hamburg, Germany

\section{Introduction}

Multiple randomized controlled trials (RCTs) have demonstrated the efficacy of endovascular treatment (EVT) among patients with acute ischemic stroke caused by large vessel occlusions. Several studies have reported worse outcome for females after acute ischemic stroke compared to males [1-5]; however, conflicting results were reported on sex differences in outcome after stroke thrombectomy.

Post hoc analyses of RCTs on stroke thrombectomy within the HERMES collaboration suggested that sex does not influence functional outcome after EVT and demonstrated a similar proportion of both women and men, achieving functional independence 90 days after intervention [6]. Similar results were obtained in a pooled analysis of patients from different trial cohorts, which did not find a gender difference in outcome at 90 days, although females were older and had higher rates of atrial fibrillation [7]. Con- 
versely, an analysis of the MR CLEAN trial reported that women were less likely to benefit from EVT with a lower proportion of independence before stroke and higher rates of serious adverse events and mortality in women than in men [8]. Thus, it is still largely unknown whether outcome after stroke thrombectomy differs between women and men. Of note, comparable studies in nonclinical trial populations are scarce. Identifying sex differences in outcome after EVT in a real-world setting may lead to targeted approaches for patient selection or sex-specific rehabilitation therapies.

The objective of our study was to determine whether sex is associated with outcome of stroke thrombectomy in clinical practice.

\section{Methods}

\section{Data Collection}

The patients analyzed in this study were derived from the German Stroke Registry-Endovascular Treatment (GSRET; ClinicalTrials.gov, identifier: NCT03356392). The GSR-ET is an ongoing prospective, multicenter registry of 25 participating sites in Germany including acute ischemic stroke patients with proximal large vessel occlusion of the anterior and posterior circulation treated by EVT. The study design and major findings had been reported previously $[9$, 10]. For this analysis, we included patients enrolled in the registry between June 2015 and April 2018.

The decision for EVT was made by an interdisciplinary team including vascular neurologists and interventional neuroradiologists on a case by case basis. Patients were older than 18 years.

Patients' age, the time elapsed from symptom onset to imaging, baseline National Institutes of Health Stroke Scale (NIHSS) score, occlusion site, the Alberta Stroke Program Early CT Score (ASPECTS), the prestroke disability assessed by the modified Rankin scale (mRS), the results of multiparametric imaging with computed tomography perfusion or magnetic resonance imaging to identify potentially salvageable brain tissue were all considered for treatment decision. Intravenous thrombolysis therapy (IVT) was applied prior to intervention as appropriate according to national and international guidelines [11, 12]. Imaging data were analyzed and reported by the local centers.

The mRS score of the patients was collected 3 months after the stroke and provided by each study site. The mRS was assessed by a well-trained investigator, who was blinded to patient variables including the results of EVT.

Patients with missing data on follow-up assessments at 90 days were excluded from this subgroup analysis.

\section{Statistical Analysis}

Standard descriptive statistics were reported as median and interquartile range or continuous variables and numbers and percentages for categorical variables. For between-group comparisons of categorical variables, $\chi^{2}$-tests or Fisher's exact tests were used, as appropriate. Mann-Whitney $U$ tests were employed for continuous variables.

Multivariable binary logistic regression analyses were applied to identify predictors of an independent outcome (defined as mRS 0-2) and of death (mRS 6) 90 days after stroke, and whether sex was associated with outcome. Moreover, ordinal regression analysis was performed to identify predictors of a worse outcome assessed by higher mRS scores at 90 days.

Besides sex, particular variables, which were known predictors of outcome after stroke thrombectomy, were included: age, NIHSS score on admission, ASPECTS as continuous independent variables, and concomitant IVT, successful reperfusion (defined by modified treatment in cerebral ischemia score [mTICI] $2 \mathrm{~b} / 3$ ) and prestroke functional impairment assessed by a mRS $>1$ as dichotomous independent variables. The time from symptom onset to recanalization was reported in less than $75 \%$ of all subjects, so that the variable was excluded from the primary analysis.

Since the variable ASPECTS had more than $10 \%$ missing values, the analyses were run in two settings that differed with respect to the included variables contained in the initial model and to the total amount of patients in which complete information on the different variables was available:

- Model 1: containing all independent variables except ASPECTS $(n=2151)$

- Model 2: containing all independent variables including ASPECTS $(n=1667)$

The resulting odds ratios with $95 \%$ confidence intervals and $p$ values are presented. Analysis was exploratory and $p$ values $<0.05$ were considered statistically significant without correction for multiple testing. All tests were twosided. Statistical analysis was performed using SPSS (Version 25.0; IBM, Armonk, NY, USA).

\section{Results}

\section{Patient Data}

In total, 2637 patients treated by EVT were consecutively enrolled in the registry during the study period. With respect to the primary outcome, data on follow-up assessment at 90 days were missing in 321 subjects, leaving 2316 patients for this analysis. The baseline data of the patients 
Table 1 Patient characteristics by sex

\begin{tabular}{|c|c|c|c|}
\hline & $\begin{array}{l}\text { Females } \\
(n=1170,50.5 \%)\end{array}$ & $\begin{array}{l}\text { Males } \\
(n=1146,49.5 \%)\end{array}$ & $P$ value \\
\hline Age in years, median (IQR) & $78(69-84)$ & $72(61-79)$ & $<0.001$ \\
\hline Baseline NIHSS score, median (IQR) & $\begin{array}{l}15(10-19) \\
(n=1155)\end{array}$ & $\begin{array}{l}15(9-19) \\
(n=1133)\end{array}$ & 0.115 \\
\hline Prestroke $m R S>1, n(\%)$ & $281 / 1131(24.8)$ & $155 / 1098(14.1)$ & $<0.001$ \\
\hline Living status before admission & & & $<0.001$ \\
\hline Home, $n(\%)$ & $924 / 1111(83.2)$ & $1117 / 1084(93.8)$ & \\
\hline Nursing at home, $n(\%)$ & $64 / 1111(5.8)$ & $28 / 1084(2.6)$ & \\
\hline Nursing home, $n(\%)$ & 123/1111 (11.1) & $39 / 1084(3.6)$ & \\
\hline \multicolumn{4}{|l|}{ Pre-existing comorbidities } \\
\hline Arterial hypertension, $n(\%)$ & $916 / 1161(78.9)$ & $816 / 1135(71.9)$ & $<0.001$ \\
\hline Hypercholesterolemia, $n(\%)$ & $370 / 1160(31.9)$ & $404 / 1131(35.7)$ & 0.053 \\
\hline Diabetes mellitus, $n(\%)$ & $234 / 1164(20.1)$ & $255 / 1135(22.5)$ & 0.166 \\
\hline Atrial fibrillation, $n(\%)$ & $540 / 1162(46.5)$ & $393 / 1131(34.7)$ & $<0.001$ \\
\hline Drip 'n ship, $n(\%)$ & $542 / 1170(46.3)$ & $561 / 1146(49.0)$ & 0.205 \\
\hline Anterior circulation infarction, $n(\%)$ & $1029 / 1134(90.7)$ & $965 / 1122(86.0)$ & $<0.001$ \\
\hline ASPECTS, median (IQR) & $\begin{array}{l}9(7-10) \\
(n=901)\end{array}$ & $\begin{array}{l}9(7-10) \\
(n=863)\end{array}$ & 0.897 \\
\hline$I V T, n(\%)$ & $649 / 1154(56.2)$ & $637 / 1141(55.8)$ & 0.843 \\
\hline Symptom onset to groin puncture, median (IQR) & $\begin{array}{l}195(149.25-270) \\
(n=644)\end{array}$ & $197(140.5-274.5)(n=705)$ & 0.616 \\
\hline Symptom onset to recanalization, median (IQR) & $\begin{array}{l}240(190-318) \\
(n=525)\end{array}$ & $\begin{array}{l}250(183-322.5) \\
(n=597)\end{array}$ & 0.971 \\
\hline TICI $2 b / 3, n(\%)$ & $942 / 1140(82.6)$ & 934/1128 (82.8) & 0.915 \\
\hline $\begin{array}{l}\text { Adverse events during treatment, } n(\%) \\
\text { (e.g. perforation, dissection) }\end{array}$ & $162 / 1157(14.0)$ & $139 / 1129(12.3)$ & 0.232 \\
\hline NIHSS score 24 h after treatment, median (IQR) & $\begin{array}{l}11(4-20) \\
(n=1027)\end{array}$ & $\begin{array}{l}10(4-20) \\
(n=992)\end{array}$ & 0.093 \\
\hline mRS score $24 \mathrm{~h}$ after treatment, median (IQR) & $\begin{array}{l}5(3-5) \\
(n=1009)\end{array}$ & $\begin{array}{l}5(3-5) \\
(n=994)\end{array}$ & 0.076 \\
\hline $\begin{array}{l}\text { Adverse events } 24 \text { after treatment, } n(\%) \\
\text { (e.g. groin hematoma, malignant infarction) }\end{array}$ & $304 / 1146(26.5)$ & $294 / 1128(26.1)$ & 0.802 \\
\hline Any ICH within $24 h$ after treatment, $n(\%)$ & $162 / 1170(13.8)$ & $139 / 1146(12.1)$ & 0.219 \\
\hline NIHSS score at discharge, median (IQR) & $\begin{array}{l}5(2-13) \\
(n=907)\end{array}$ & $\begin{array}{l}5(2-12) \\
(n=922)\end{array}$ & 0.480 \\
\hline$m R S$ score at discharge, median $(I Q R)$ & $\begin{array}{l}4(2-5) \\
(n=1140)\end{array}$ & $\begin{array}{l}4(2-5) \\
(n=1120)\end{array}$ & 0.065 \\
\hline $\begin{array}{l}\text { Adverse events until discharge, } n(\%) \\
\text { (e.g. infections, recurrent stroke) }\end{array}$ & $392 / 1105(35.5)$ & $384 / 1082(35.5)$ & 0.994 \\
\hline Stroke etiology & & & $<0.001$ \\
\hline Atrial fibrillation, $n(\%)$ & $653 / 1152(56.7)$ & $487 / 1129(43.1)$ & \\
\hline Atherosclerosis, $n(\%)$ & $236 / 1152(20.5)$ & $338 / 1129(29.9)$ & \\
\hline Other, $n(\%)$ & $52 / 1152(4.5)$ & $59 / 1129(5.2)$ & \\
\hline Undetermined, $n(\%)$ & 195/1152 (16.9) & $206 / 1129(18.2)$ & \\
\hline Dissection, $n(\%)$ & $16 / 1152(1.4)$ & $16 / 1129(1.4)$ & \\
\hline Destination after discharge & & & $<0.001$ \\
\hline Home, $n(\%)$ & $214 / 925(23.1)$ & 252/927 (27.2) & \\
\hline Neurorehabilitation, $n(\%)$ & $507 / 925(54.8)$ & $515 / 927(55.6)$ & \\
\hline Hospital, $n(\%)$ & $163 / 925(17.6)$ & 147/927 (15.9) & \\
\hline Nursing home, $n(\%)$ & $41 / 925(4.4)$ & $13 / 927(1.4)$ & \\
\hline
\end{tabular}


Table 1 (Continued)

\begin{tabular}{llll}
\hline & $\begin{array}{l}\text { Females } \\
(n=1170,50.5 \%)\end{array}$ & $\begin{array}{l}\text { Males } \\
(n=1146,49.5 \%)\end{array}$ & $P$ value \\
\hline$m R S$ at 90 days, median $(I Q R)$ & $4(2-6)$ & $3(1-6)$ & 0.001 \\
$m R S$ 0-2 at 90 days, $n(\%)$ & $389 / 1170(33.2)$ & $465 / 1146(40.6)$ & $<0.001$ \\
$m R S$ 5/6 at 90 days, $n(\%)$ & $477 / 1170(40.8)$ & $417 / 1146(36.4)$ & 0.030 \\
$m R S 6$ at 90 days, $n(\%)$ & $359 / 1170(30.7)$ & $303 / 1146(26.4)$ & 0.024 \\
\hline
\end{tabular}

Significant values in italics

$I Q R$ interquartile range, NIHSS National Institutes of Health Stroke Scale, $m R S$ modified Rankin scale, IVT intravenous thrombolysis,

ASPECTS Alberta Stroke Program Early CT Score, $m$ TICI modified thrombolysis in cerebral infarction score, ICH intracerebral hemorrhage

with missing outcome values did not differ from those with available 90-day follow-up information (Supplemental Table e1), indicating that a significant bias of patients lost to follow-up was not to be expected.

In the cohort of 2316 patients, 1170 patients $(50.5 \%)$ were female and 1146 (49.5\%) were male. Results of group comparisons by sex are displayed in Table 1 .

Women were older than men (median age 78 years vs. 72 years, $p<0.001$ ), and were more likely to be diagnosed with the pre-existing comorbidities arterial hypertension (78.9\% vs. $71.9 \%, p<0.001)$ and atrial fibrillation $(46.5 \%$ vs. $34.7 \%, p<0.001)$. In addition, a higher proportion of women had a prestroke mRS $>1(24.8 \%$ vs. $14.1 \%$, $p<0.001)$. Consistent with these findings, the living status before admission differed between both subgroups of patients $(p<0.001)$. A higher proportion of females received nursing care, either at home (5.8\% vs. $2.6 \%)$ or at a nursing home $(11.1 \%$ vs. $3.6 \%)$, instead of living at home $(83.2 \%$ vs. $93.8 \%$ ). Moreover, women suffered more frequently from vessel occlusions of the anterior circulation $(90.7 \%$ vs. $86.0 \%, p<0.001)$. Other baseline characteristics were comparable between women and men.

Functional outcome 90 days after stroke thrombectomy differed significantly between women and men, with $32.2 \%$ females vs. $40.6 \%$ males $(p<0.001)$ being independent 90 days after stroke. Accordingly, mortality was higher in women $(30.7 \%$ vs. $26.4 \%, p=0.024)$ and a larger proportion of women had a poor outcome defined by a mRS 5 and $6(40.8 \%$ vs. $36.4 \%, p=0.033)$. Fig. 1 illustrates the distribution of each $\mathrm{mRS}$ score among females and males at 90 days.

\section{Binary Logistic Regression Analysis}

In univariate logistic regression analyses, all variables of interest including sex showed a significant association with an independent outcome and death 90 days after stroke (Table 2a and Supplemental Table e2a). In model 1 of the multivariable regression analyses, a lower age, a lower baseline NIHSS score, successful reperfusion, prestroke functional independence and a concomitant IVT were significantly associated with independent outcome (Table 2b). In model 2 the ASPECTS predicted independent outcome in addition to the aforementioned variables (Table $2 b$, Fig. 2). Sex did not predict outcome in adjusted analyses.

The continuous variable symptom onset-to-recanalization was not associated with independent outcome when included in a secondary univariate and multivariate analysis (data not shown).

In line with this, a higher age, a higher baseline NIHSS score, a prestroke mRS score $>1$, no concomitant IVT and unsuccessful reperfusion were significant predictors of death (model 1; Supplemental Table e2b). After including the ASPECT score to this adjusted analysis, a lower ASPECTS was associated with death in addition to the abovementioned variables (model 2; Supplemental Table e2b). Sex did not predict outcome in this multivariable regression analysis. In a secondary analysis, symptom onsetto-recanalization was not associated with death (data not shown).

\section{Ordinal Regression Analyses}

In univariate analyses, all variables of interest were significantly associated with the ordinal mRS score 90 days after stroke (Supplemental Table e3a). In adjusted analyses, a higher age, a higher baseline NIHSS score, a prestroke $\mathrm{mRS}$ score $>1$, no concomitant IVT and unsuccessful reperfusion were associated with worse outcome assessed by higher mRS scores at 90 days (model 1; Supplemental Table e3b). In model 2 a higher ASPECTS was associated with lower mRS scores (Supplemental Table e3b). In a secondary analysis, the variable symptom onset-to-recanalization did not show any association with the ordinal mRS score at 90 days (data not shown).

\section{Discussion}

In this large prospective multicenter study of stroke patients treated by thrombectomy in clinical practice, we observed a worse functional outcome and higher mortality at 90 days in women; however, after adjustment for crucial 
Fig. 1 Distribution of the mRS scores by sex at 90 days. The distribution of the mRS scores of women and men 90 days after stroke thrombectomy is displayed. $m R S$ modified Rankin Scale
Fig. 2 Predictors of outcome after stroke thrombectomy in clinical practice. Forest plot showing adjusted analyses (adjusted OR and $95 \% \mathrm{CI}$ ) of predictors of outcome after stroke thrombectomy in this patient cohort of clinical practice. Age, NIHSS, prestroke mRS, IVT, ASPECTS and successful reperfusion were significant predictors of independent outcome, while sex was not associated with outcome. $a O R$ adjusted odds ratio, $\mathrm{CI}$ confidence interval, NIHSS National Institutes of Health Stroke Scale, $m R S$ modified Rankin Scale, IVT intravenous thrombolysis, ASPECTS Alberta Stroke Program Early CT Score, mTICI modified thrombolysis in cerebral infarction score
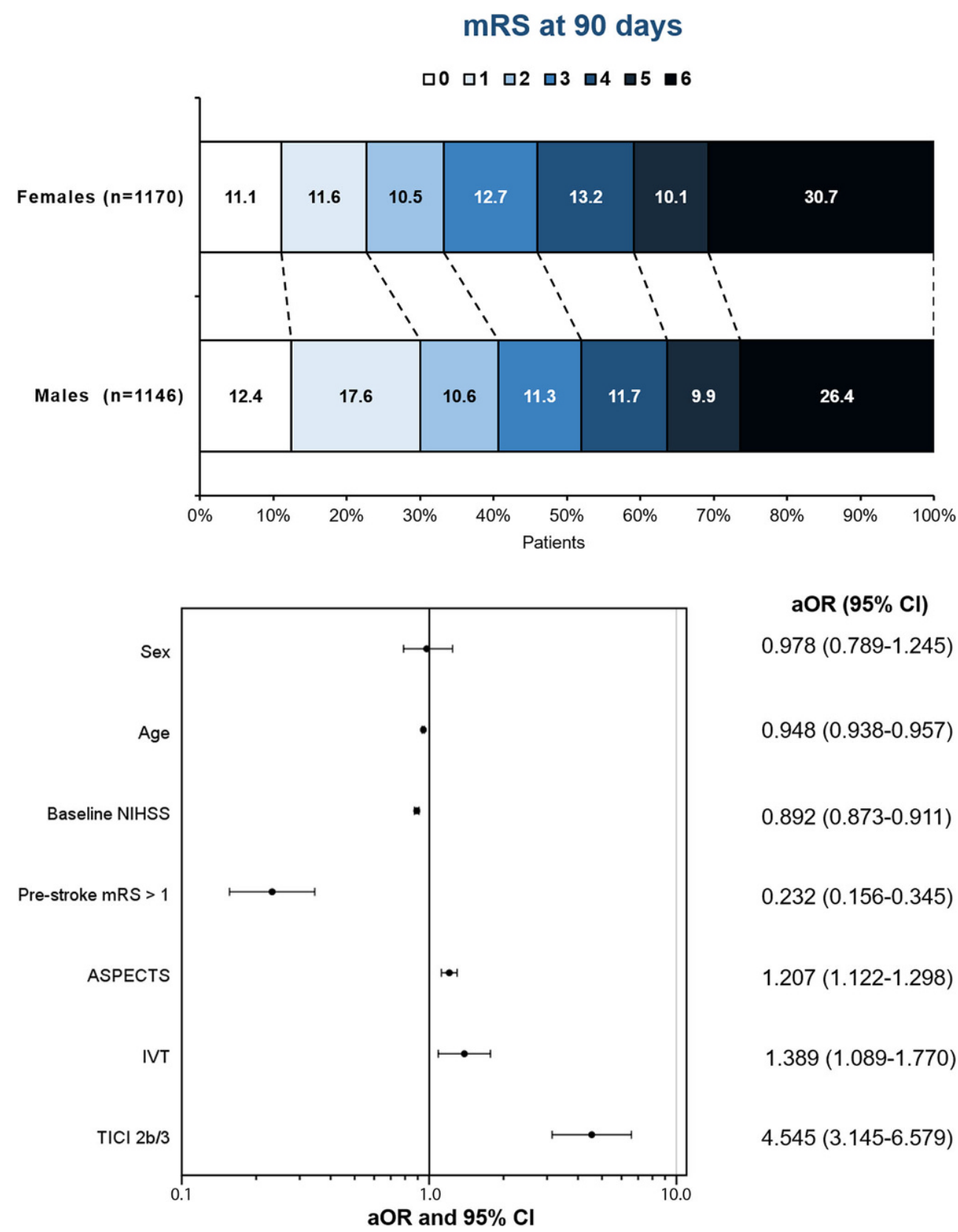

aOR $(95 \% \mathrm{Cl})$

$0.978(0.789-1.245)$

$0.948(0.938-0.957)$

$0.892(0.873-0.911)$

$0.232(0.156-0.345)$

$1.207(1.122-1.298)$

$1.389(1.089-1.770)$

4.545 (3.145-6.579) confounders there was no association of sex with independent outcome.

These study results are consistent with previous studies, which did not find sex differences in outcome 90 days after stroke thrombectomy [6, 7]. In the HERMES pooled analysis of RCTs of stroke thrombectomy both women and men experienced comparable functional outcome and treatment effect of EVT was similar[6], despite women being older, similar as in our analysis. In contrast, in the MR CLEAN trial lower rates of functional independence and higher mortality were observed in women, together with a significant sex by treatment interaction with no significant treatment benefit in women [8]; however, these findings are solitary and have to be interpreted with caution, as the analysis was a post hoc subgroup analysis and the authors themselves suggested that the results may be explained by a play of chance.

Our analysis adds to the available studies of sex differences in outcome after stroke thrombectomy, as it is based on an independent large prospective registry of EVT in clinical practice. Trial populations are different from realworld patient cohorts resulting from the strict inclusion and exclusion criteria of clinical trials which are meant to ensure enrolment of those patients that are most likely to benefit from the investigational treatment. With respect to sex differences, women are frequently underrepresented in 
Table 2 Predictors of independent outcome

\begin{tabular}{lll}
\hline a) Univariate binary logistic regression analyses & \\
& OR $^{\mathrm{a}}(95 \% \mathrm{CI})$ & $P$ values \\
Sex $(n=2316)$ & 0.729 & $<0.001$ \\
& $(0.616-0.864)$ & \\
Age $(n=2316)$ & 0.947 & $<0.001$ \\
& $(0.940-0.954)$ & \\
Baseline NIHSS score & 0.898 & $<0.001$ \\
$(n=2288)$ & $(0.885-0.911)$ & \\
Prestroke mRS $>1$ & 0.152 & $<0.001$ \\
$(n=2229)$ & $(0.111-0.204)$ & \\
IVT $(n=2295)$ & 1.582 & $<0.001$ \\
& $(1.330-1.880)$ & \\
TICI2b/3 $(n=2268)$ & 3.968 & $<0.001$ \\
& $(2.967-5.291)$ & \\
ASPECTS $(n=1764)$ & 1.244 & $<0.001$ \\
& $(1.171-1.322)$ &
\end{tabular}

b) Multivariable binary logistic regression analyses

$P$

Model 1: All independent variables except ASPECTS $(n=2151)$

$0.986 \quad 0.897$

(0.799-0.217)

Age

$0.952<0.001$

(0.944-0.961)

Baseline NIHSS score

$0.900<0.001$

(0.855-0.915)

Prestroke mRS $>1$

0.225

(0.159-0.319)

IVT

1.645

$<0.001$

(1.333-2.028)

$\mathrm{TICI} 2 \mathrm{~b} / 3$

$4.831<0.001$

(3.460-6.757)

Model 2: All independent variables including ASPECTS $(n=1667)$

Sex

$0.978 \quad 0.862$

(0.789-1.245)

Age

0.948

$<0.001$

(0.938-0.957)

Baseline NIHSS

0.892

(0.873-0.911)

Prestroke mRS $>1$

0.232

$(0.156-0.345)$

IVT

1.389

$(1.089-1.770)$

ASPECTS score

1.207

(1.122-1.298)

$\mathrm{TICI} 2 \mathrm{~b} / 3$

4.545

$(3.145-6.579)$

OR odds ratio, $C I$ confidence interval, NIHSS National Institutes of Health Stroke Scale, $m R S$ modified Rankin Scale, IVT intravenous thrombolysis, $m$ TICI modified thrombolysis in cerebral infarction score, ASPECTS Alberta Stroke Program Early CT Score ${ }^{\mathrm{a}} \mathrm{OR}>1$ indicate higher probabilities of independent outcome (mRSO2) at 90 days clinical trials [13], while in the real world stroke affects women and men in equal proportions. Moreover, stroke patients in trials are usually younger and have fewer comorbidities and less prestroke functional impairments than patients treated in clinical practice $[1,14,15]$. Comparing baseline characteristics of our study population to that from the HERMES analysis, some of these observations are confirmed. In HERMES, women were slightly underrepresented $(47 \%)$, although in high-income countries women experience anterior circulation strokes more often [16]. In contrast, in our cohort $50.5 \%$ of patients were female and a higher proportion of women suffered from ischemic stroke of the anterior circulation. The analysis of the HERMES trial also showed similar rates of atrial fibrillation between women and men [6], while the prevalence of atrial fibrillation is usually higher in women [17], as it was in our study cohort. Moreover, the NIHSS score on admission was lower in women compared to men in the HERMES analysis, whereas the baseline NIHSS score did not differ by sex in our patient cohort. Of note, the MR CLEAN trial had less strict inclusion criteria than other RCTs of stroke thrombectomy, resulting in a patient cohort more comparable to realworld populations than other trial cohorts. Presumably, this might explain the similar outcome results with respect to the worse outcome in unadjusted analysis in MR CLEAN as compared to our cohort.

Similar to our analysis, a recent single center study of 279 patients in a real-world setting reported that females were less likely to be independent at 90 days after stroke thrombectomy than males [18]. In contrast, another single center study of stroke thrombectomy in clinical practice comprising 145 patients, found no sex differences in clinical outcome after EVT in acute ischemic stroke patients [19]. Small patient numbers as well as differences in baseline characteristics may account for the variability in the reported outcome results. In both studies mentioned above, women were older than men; however, the latter study included females with an equal prestroke disability compared to men, in contrast to our multicenter patient cohort in which prestroke disability differed significantly by sex with a larger proportion of women exhibiting functional disability before stroke. Notably, these parameters, i.e. age and prestroke functional impairment, are known predictors of outcome after EVT [20, 21].

After adjustment for confounders of interest (in both binary logistic and ordinal regression analyses), there was no significant association of sex and functional outcome in our study. Age and prestroke mRS were also identified as predictors of functional outcome in our patient cohort and showed significant differences between women and men. Thus, both variables may at least partially explain the observed sex differences in outcome. Similar findings were reported by the INSTRUCT collaboration [22]. 
The reason for the differences in age and prestroke functional status between women and men remains elusive. One interpretation is that women take care of more preventive efforts and have healthier lifestyles resulting in a longer stroke-free life. Thus, women are older when they suffer from first-ever stroke [22]. In consequence, more age-related diseases may occur accompanied by a higher prestroke disability [23] resulting in a less capacity to recover from stroke compared to men [22]. Moreover, the facts that a worse prestroke functional status in women may lead to less clear symptoms at onset time and that women usually take stroke symptoms less seriously, together may cause a late arrival to hospital and result in longer workflow times.

Notwithstanding, it is notable that other pivotal factors, such as the baseline NIHSS score, ASPECT score, the rates of prior IVT and successful reperfusion, in fact, did predict outcome in this patient cohort but showed no sex differences. Furthermore, in-hospital variables, such as the NIHSS and mRS score $24 \mathrm{~h}$ after intervention and at discharge as well as procedure times, the rate of adverse events and the rate of any intracerebral hemorrhage, were comparable between women and men. Thus, we cannot exclude that other variables which we did not collect might also add to sex differences in stroke outcome.

\section{Limitations}

Our study has limitations. It lacks a patient group that received best medical treatment instead of EVT and, thus, we are not able to evaluate the effectiveness of EVT between women and men in clinical practice. Moreover, another important limitation is that some of the variables collected in the study had many missing values, in particular, the workflow times symptom onset-to-groin puncture and symptom onset-to-recanalization. However, this was considered in the statistical analysis. In addition, we cannot exclude a patient selection bias, since EVT was most likely performed in patients in whom a treatment benefit was assumed. Furthermore, we do not have data on other important, e.g. prestroke or postdischarge variables, which might have an impact on outcome in females.

\section{Conclusion}

In a prospective multicenter registry study of endovascular stroke treatment in clinical practice, we observed a worse functional outcome in women, which appears to be explained by differences in baseline characteristics, such as age and prestroke modified Rankin scale, between women and men. As a consequence, sex was not an independent predictor of functional independence at 90 days after adjustment for confounders.

GSR-ET Steering Committee Investigators Universitätsklinikum Hamburg-Eppendorf: Prof. Dr. C. Gerloff, Prof. Dr. J. Fiehler, Prof. Dr. G. Thomalla, Dr. med. A. Alegiani; Klinikum rechts der Isar: Dr. Boeckh-Behrens, Dr. Silke Wunderlich; Universitätsklinikum Tübingen: Prof. Dr. Ulrike Ernemann, Dr. Sven Poli; Charité-Campus Benjamin Franklin und Campus Charité Mitte, Berlin: Dr. Eberhard Siebert, Prof. Dr. Christian H. Nolte; Charité-Campus Virchow Klinikum, Berlin: Dr. Sarah Zweynert, Dr. Georg Bohner; Sana Klinikum Offenbach: Dr. med. Alexander Ludolph, Dr. med. KarlHeinz Henn; Universitätsklinikum Frankfurt/Main: Prof. Dr. Waltraud Pfeilschifter, Dr. Fee Keil; Asklepios Klinikum Altona: Prof. Dr. Joachim Röther, Prof. Dr. Bernd Eckert; Klinikum Altenburger Land: Prof. Dr. Jörg Berrouschot, Dr. Albrecht Bormann; Universitätsklinikum Bonn: Prof. Dr. László Solymosi, Prof. Dr. Gabor Petzold; Klinikum Lüneburg: Dr. Christoffer Kraemer; Universitätsklinikum München (LMU): Prof. Dr. Martin Dichgans, Dr. Steffen Tiedt, Dr. Lars Kellert, Dr. Franziska Dorn; Klinikum Osnabrück: Dr. Martina Petersen, Prof. Dr. Florian Stögbauer; Bezirkskrankenhaus Günzburg: Dr. med. Michael Braun, Prof. Dr. Gerhard F. Hamann; Universitätsmedizin Mainz: Prof. Dr. Klaus Gröschel, Dr. Timo Uphaus

Author Contribution MDC: Substantial contributions to the conception and design of the work. Acquisition, analysis and interpretation of data. Drafting the work and revising it critically for important intellectual content.

ES, JF, CG: Analysis and interpretation of data. Revising the work critically for important intellectual content.

FF, LM, AA, CB: Acquisition of data. Revising the work critically for important intellectual content.

GT: Substantial contributions to the conception and design of the work. Analysis and interpretation of data. Drafting the work and revising it critically for important intellectual content.

All authors approved the version to be published and have agreed to be accountable for all aspects of the work in ensuring that questions related to the accuracy or integrity of any part of the work are appropriately investigated and resolved.

Funding Open Access funding enabled and organized by Projekt DEAL.

\section{Compliance with ethical guidelines}

Conflict of interest M. Deb-Chatterji, E. Schlemm, F. Flottmann, L. Meyer, C. Brekenfeld declare that they have no competing interests. A. Alegiani reports honoraria as speaker from Bayer Vital. J. Fiehler receives research support from the German Ministry of Science and Education (BMBF), German Ministry of Economy and Innovation (BMWi), German Research Foundation (DFG), European Union (EU), Hamburgische Investitions- und Förderbank (IFB), Medtronic, Microvention, Philips, Stryker; and serves as a consultant for Acandis, Boehringer Ingelheim, Cerenovus, Evasc Neurovascular, MD Clinicals, Medtronic, Medina, Microvention, Penumbra, Route92, Stryker, Transverse Medical. C. Gerloff serves on scientific advisory boards for Bayer Vital, Boehringer Ingelheim, Acticor Biotech, Amgen, and Prediction Biosciences; has received funding for travel and/or speaker/consulting honoraria from Bayer Vital, Boehringer Ingelheim, Sanofi Aventis, Amgen, EBS Technologies, GlaxoSmithKline, Lundbeck, Pfizer, Silk Road Medical, and UCB, and Abbott; serves on editorial boards for INFO Neurologie \& Psychiatrie and Aktuelle Neurologie and as editor of textbook Therapie und Verlauf neurologischer Erkrankungen; has received grants to supporting employees/scientists 
of his clinic from Merz Pharmaceuticals, Allergan, Novartis, and NeuroConn; and receives research support from Deutsche Forschungsgesellschaft, the European Union, Wegener Foundation, Schilling Foundation, and Werner-Otto-Foundation. G. Thomalla has received personal fees as consultant or lecturer from Acandis, Bayer, Boehringer Ingelheim, Bristol-Myers Squibb/Pfizer, Daichi Sankyo, Stryker, and research grants from Bayer, Federal Ministry for Economic Affairs and Energy (BMWi), Corona-Foundation, German Research Foundation (DFG), Else Kröner-Fresenius Foundation, European Union (Horizon 2020), German Innovation Fund.

Ethical standards The study was approved by the responsible ethics committees of all participating sites, and was performed in accordance with the ethical standards laid down in the 1964 Declaration of Helsinki and its later amendments. Written informed consent was obtained from the patient or the proxy prior inclusion in the study. Consent was waived if patients died before consent could be obtained or lacked the capacity to give consent and no proxy was available.

Open Access This article is licensed under a Creative Commons Attribution 4.0 International License, which permits use, sharing, adaptation, distribution and reproduction in any medium or format, as long as you give appropriate credit to the original author(s) and the source, provide a link to the Creative Commons licence, and indicate if changes were made. The images or other third party material in this article are included in the article's Creative Commons licence, unless indicated otherwise in a credit line to the material. If material is not included in the article's Creative Commons licence and your intended use is not permitted by statutory regulation or exceeds the permitted use, you will need to obtain permission directly from the copyright holder. To view a copy of this licence, visit http://creativecommons.org/licenses/by/4. $0 /$.

\section{References}

1. Di Carlo A, Lamassa M, Baldereschi M, Pracucci G, Basile AM, Wolfe CD, Giroud M, Rudd A, Ghetti A, Inzitari D; European BIOMED Study of Stroke Care Group. Sex differences in the clinical presentation, resource use, and 3-month outcome of acute stroke in Europe: data from a multicenter multinational hospitalbased registry. Stroke. 2003;34:1114-9.

2. Niewada M, Kobayashi A, Sandercock PA, Kamiński B, Członkowska A; International Stroke Trial Collaborative Group. Influence of gender on baseline features and clinical outcomes among 17,370 patients with confirmed ischaemic stroke in the international stroke trial. Neuroepidemiology. 2005;24:123-8.

3. Lisabeth LD, Reeves MJ, Baek J, Skolarus LE, Brown DL, Zahuranec DB, Smith MA, Morgenstern LB. Factors influencing sex differences in poststroke functional outcome. Stroke. 2015;46:860-3.

4. Persky RW, Turtzo LC, McCullough LD. Stroke in women: disparities and outcomes. Curr Cardiol Rep. 2010;12:6-13.

5. Silva GS, Lima FO, Camargo EC, Smith WS, Lev MH, Harris GJ, Halpern EF, Koroshetz W, Furie KL. Gender differences in outcomes after ischemic stroke: role of ischemic lesion volume and intracranial large-artery occlusion. Cerebrovasc Dis. 2010;30:470-5.

6. Chalos V, de Ridder IR, Lingsma HF, Brown S, van Oostenbrugge RJ, Goyal M, Campbell BCV, Muir KW, Guillemin F, Bracard S, White P, Dávalos A, Jovin TG, Hill MD, Mitchell PJ, Demchuk AM, Saver JL, van Zwam WH, Dippel DWJ; HERMES Collaborators. Does Sex Modify the Effect of Endovascular Treatment for Ischemic Stroke? Stroke. 2019;50:2413-9.

7. Sheth SA, Lee S, Warach SJ, Gralla J, Jahan R, Goyal M, Nogueira RG, Zaidat OO, Pereira VM, Siddiqui A, Lutsep H, Liebeskind DS, McCullough LD, Saver JL. Sex Differences in Outcome After
Endovascular Stroke Therapy for Acute Ischemic Stroke. Stroke. 2019;50:2420-7.

8. de Ridder IR, Fransen PS, Beumer D, Berkhemer OA, van den Berg LA, Wermer MJ, Lingsma H, van Zwam WH, Roos YB, van Oostenbrugge RJ, Majoie CB, van der Lugt A, Dippel DW. Is Intra-Arterial Treatment for Acute Ischemic Stroke Less Effective in Women than in Men? Interv Neurol. 2016;5:174-8.

9. Alegiani AC, Dorn F, Herzberg M, Wollenweber FA, Kellert L, Siebert E, Nolte $\mathrm{CH}$, von Rennenberg R, Hattingen E, Petzold GC, Bode FJ, Pfeilschifter W, Schäfer JH, Wagner M, Röther J, Eckert B, Kraft P, Pham M, Boeckh-Behrens T, Wunderlich S, Bernkopf K, Reich A, Wiesmann M, Mpotsaris A, Psychogios M, Liman J, Maier I, Berrouschot J, Bormann A, Limmroth V, Spreer J, Petersen M, Krause L, Lowens S, Kraemer C, Zweynert S, Lange KS, Thonke S, Kastrup A, Papanagiotou P, Alber B, Braun M, Fiehler J, Gerloff C, Dichgans M, Thomalla G. Systematic evaluation of stroke thrombectomy in clinical practice: The German Stroke Registry Endovascular Treatment. Int J Stroke. 2019 Jun;14(4):372-380. doi: 10.1177/1747493018806199. Epub 2018 Oct 22. Erratum in: Int J Stroke. 2018 Dec 17;:1747493018816194. Erratum in: Eur J Prev Cardiol. 2020;27:NP16.

10. Wollenweber FA, Tiedt S, Alegiani A, Alber B, Bangard C, Berrouschot J, Bode FJ, Boeckh-Behrens T, Bohner G, Bormann A, Braun M, Dorn F, Eckert B, Flottmann F, Hamann GF, Henn KH, Herzberg M, Kastrup A, Kellert L, Kraemer C, Krause L, Lehm M, Liman J, Lowens S, Mpotsaris A, Papanagiotou P, Petersen M, Petzold GC, Pfeilschifter W, Psychogios MN, Reich A, von Rennenberg R, Röther J, Schäfer JH, Siebert E, Siedow A, Solymosi L, Thonke S, Wagner M, Wunderlich S, Zweynert S, Nolte CH, Gerloff C, Thomalla G, Dichgans M, Fiehler J. Functional Outcome Following Stroke Thrombectomy in Clinical Practice. Stroke. 2019;50:2500-6.

11. Powers WJ, Rabinstein AA, Ackerson T, Adeoye OM, Bambakidis NC, Becker K, Biller J, Brown M, Demaerschalk BM, Hoh B, Jauch EC, Kidwell CS, Leslie-Mazwi TM, Ovbiagele B, Scott PA, Sheth KN, Southerland AM, Summers DV, Tirschwell DL; American Heart Association Stroke Council. 2018 Guidelines for the Early Management of Patients With Acute Ischemic Stroke: A Guideline for Healthcare Professionals From the American Heart Association/ American Stroke Association. Stroke. 2018;49:e46-110. Erratum in: Stroke. 2018;49:e138.

12. German Society of Neurology (DGN). Akuttherapie des ischämischen schlaganfalls - Rekanalisierende Therapie (Ergänzung 2015) 2015 [Available from: https://dgn.org/leitlinien/030-140-rekanalisie rende-therapie-ergaenzung-akuttherapie-schlaganfall-special/.

13. Tsivgoulis G, Katsanos AH, Caso V. Under-representation of women in stroke randomized controlled trials: inadvertent selection bias leading to suboptimal conclusions. Ther Adv Neurol Disord. 2017;10:241-4.

14. Jansen IGH, Mulder MJHL, Goldhoorn RB; MR CLEAN Registry investigators. Endovascular treatment for acute ischaemic stroke in routine clinical practice: prospective, observational cohort study (MR CLEAN Registry). BMJ. 2018;360:k949.

15. Román LS, Menon BK, Blasco J, Hernández-Pérez M, Dávalos A, Majoie CBLM, Campbell BCV, Guillemin F, Lingsma H, Anxionnat R, Epstein J, Saver JL, Marquering H, Wong JH, Lopes D, Reimann G, Desal H, Dippel DWJ, Coutts S, du Mesnil de Rochemont R, Yavagal D, Ferre JC, Roos YBWEM, Liebeskind DS, Lenthall R, Molina C, Al Ajlan FS, Reddy V, Dowlatshahi D, Sourour NA, Oppenheim C, Mitha AP, Davis SM, Weimar C, van Oostenbrugge RJ, Cobo E, Kleinig TJ, Donnan GA, van der Lugt A, Demchuk AM, Berkhemer OA, Boers AMM, Ford GA, Muir KW, Brown BS, Jovin T, van Zwam WH, Mitchell PJ, Hill MD, White P, Bracard S, Goyal M; HERMES collaborators. Imaging features and safety and efficacy of endovascular stroke treatment: 
a meta-analysis of individual patient-level data. Lancet Neurol. 2018;17:895-904. Erratum in: Lancet Neurol. 2018;17:e2-3.

16. Reeves MJ, Bushnell CD, Howard G, Gargano JW, Duncan PW, Lynch G, Khatiwoda A, Lisabeth L. Sex differences in stroke: epidemiology, clinical presentation, medical care, and outcomes. Lancet Neurol. 2008;7:915-26.

17. Piccini JP, Peterson ED; Outcomes Registry for Better Informed Treatment of Atrial Fibrillation Investigators and Patients. Differences in Clinical and Functional Outcomes of Atrial Fibrillation in Women and Men-Reply. JAMA Cardiol. 2017;2:108-10.

18. Madsen TE, DeCroce-Movson E, Hemendinger M, McTaggart RA, Yaghi S, Cutting S, Furie KL, Saad A, Siket MS, Jayaraman MV. Sex differences in 90-day outcomes after mechanical thrombectomy for acute ischemic stroke. J Neurointerv Surg. 2019;11:221-5.

19. Carvalho A, Cunha A, Gregório T, Paredes L, Costa H, Veloso M, Castro S, Ribeiro M, Barros PJG. Is the Efficacy of Endovascular Treatment for Acute Ischemic Stroke Sex-Related. Interv Neurol. 2018;7:42-7.

20. Meyer L, Alexandrou M, Leischner H, Flottmann F, Deb-Chatterji M, Abdullayev N, Maus V, Politi M, Roth C, Kastrup A, Thomalla
G, Mpotsaris A, Fiehler J, Papanagiotou P. Mechanical thrombectomy in nonagenarians with acute ischemic stroke. J Neurointerv Surg. 2019;11:1091-4.

21. Deb-Chatterji M, Pinnschmidt H, Flottmann F, Leischner H, Broocks G, Alegiani A, Brekenfeld C, Fiehler J, Gerloff C, Thomalla G; GSR-ET Investigators. Predictors of independent outcome of thrombectomy in stroke patients with large baseline infarcts in clinical practice: a multicenter analysis. J Neurointerv Surg. 2020;12:1064-8.

22. Phan HT, Blizzard CL, Reeves MJ, Thrift AG, Cadilhac DA, Sturm J, Heeley E, Otahal P, Vemmos K, Anderson C, Parmar P, Krishnamurthi R, Barker-Collo S, Feigin V, Bejot Y, Cabral NL, Carolei A, Sacco S, Chausson N, Olindo S, Rothwell P, Silva C, Correia M, Magalhães R, Appelros P, Kõrv J, Vibo R, Minelli C, Gall SL. Factors contributing to sex differences in functional outcomes and participation after stroke. Neurology. 2018;90:e1945-53.

23. Gur AY, Tanne D, Bornstein NM, Milo R, Auriel E, Shopin L, Koton S; NASIS Investigators. Stroke in the very elderly: characteristics and outcome in patients aged $\geq 85$ years with a first-ever ischemic stroke. Neuroepidemiology. 2012;39:57-62. 